\title{
Applying the evaluation results of porosity-permeability distribution characteristics based on hydraulic flow units (HFU) to improve the reliability in building a 3D geological model, GD field, Cuu Long Basin
}

\author{
Ngoc Ba Thai ${ }^{1} \cdot$ Xuan Van Tran ${ }^{1} \cdot$ Khanh Quang Do $^{1}$. \\ Quang Trong Hoang ${ }^{1}$ Tuan Manh Nguyen ${ }^{2}$
}

Received: 7 December 2016/ Accepted: 26 February 2017/Published online: 16 March 2017

(c) The Author(s) 2017. This article is an open access publication

\begin{abstract}
Constructing a facies model in geological modeling with two types of rock facies is not only stimulating but also necessary for modeling in a new direction to be able to reflect the interconnection of the oil body as well as heterogeneity of reservoir characteristics more clearly. The results of environmental interpretation derived from core sample data show that more than ten kinds of facies in rivers/lakes have been identified in the study area. However, predicting this kind of facies in the space of coring in wells and then simulated reservoirs as depositional facies faces many difficulties. Therefore, the simulation under lithology facies still includes reservoir and non-reservoir rocks but splits reservoir rocks into different HU types based on their porosity-permeability characteristics derived from core analysis results used in facies modeling steps. FZI values are shown on the chart by the statistical probability of reservoir rock in four HU types corresponding to four lines with different slope angles representing each HU type from the core analysis data. The newly identified HU types then are shown on the Amaefule chart plot according to the relationships between the reservoir rock quality index and normalized porosity $(\Phi z)$ for all core samples. The division of rock facies into HU types also refers to the results of sedimentary environmental interpretation from core sample data in the wells. We used the artificial neutron network method in the IP software to predict the FZI values and
\end{abstract}

Ngoc Ba Thai

tbngoc@hcmut.edu.vn

1 University of Technology, Viet Nam National University Ho Chi Minh City (VNUHCM), 268 Ly Thuong Kiet St, 10th Dist., Ho Chi Minh City 70000, Vietnam

2 PVEP-POC, 12 Tan Trao St, Dist. 7, HCMC, Vietnam then grouped them by HU type for no core sample intervals of whole sections of the wells. Based on the facies model and parameter model of porosity, saturation was built, and in-place oil reserves were calculated using the volumetric calculation function in Petrel software. One hundred realizations were run, and we chose the base case corresponding to the P50 probabilistic results to simplify its use in production simulation models. Compared with the results calculated by volumetric methods for block $\mathrm{H} 1$ and $\mathrm{H} 2$ of 102 million barrels, those of oilin-place reserves calculated from the model were more than about $3 \%$.

Keywords Hydraulic flow units (HU) · Flow zone indicator (FZI) - Reservoir quality index (RQI) - Facies model $\cdot$ Properties model

\section{Introduction}

The GD oilfield is located in the northeast of block 16-1, Cuu Long Basin, $100 \mathrm{~km}$ southeast of Vung Tau. The oil reservoir in the GD oilfield is mainly comprised of early age Miocene terrigenous sandstones in the White Tiger Lower Formation and the Tra Tan Upper Formation Olioxen later on (Fig. 1).

The GD oilfield has an en-echelon fault system that runs east northeast-west southwest and is mainly characterized by co-sedimentary faulting associated with a horizontal movement divided field structure in blocks from north to south, named H1 to H7. Most of the faults drop to the south, a few to the north. Most of the faults end in the Lower Miocene and some extend through the Middle Miocene White Tiger shale (Fig. 2). 


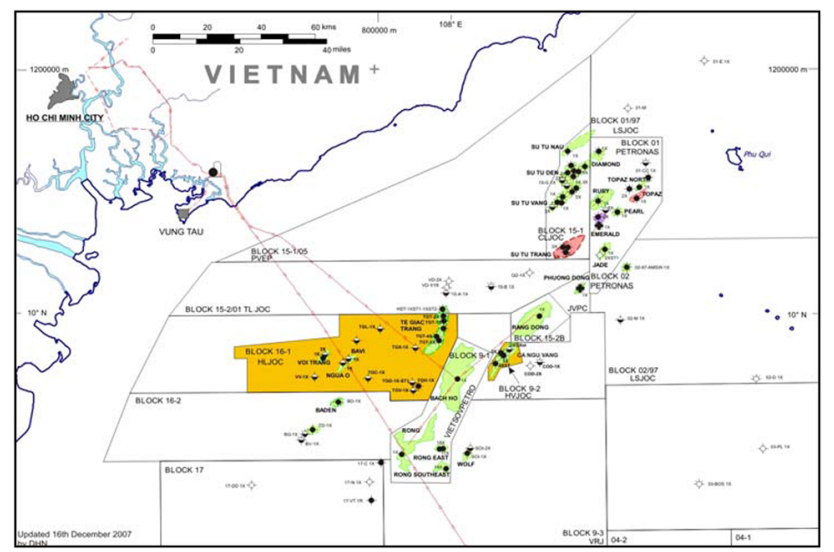

Fig. 1 Location of the GD oilfield

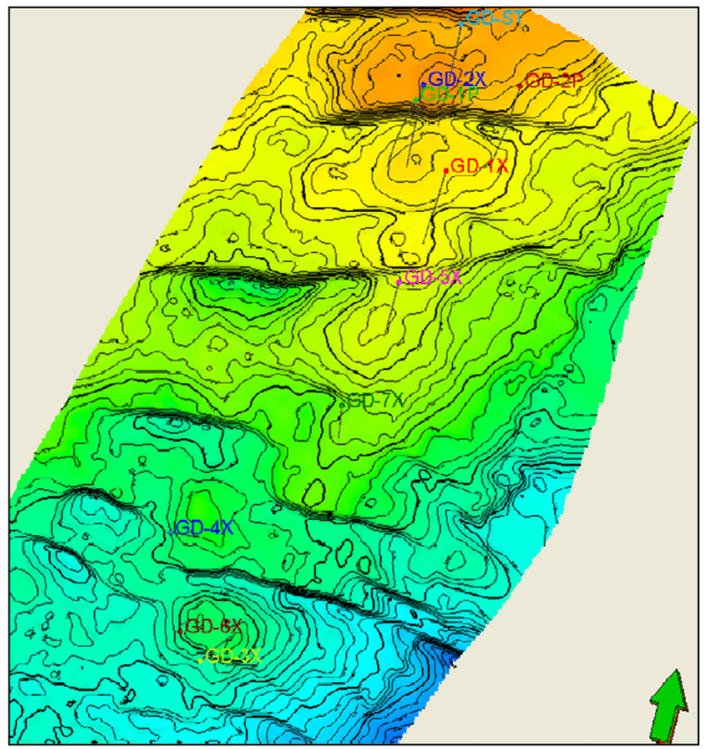

Fig. 2 Map of the cap rock structure in ILBH5.2 reservoir, GD field

The 3D geological model for Lower Miocene reservoir ILBH5.2 in the north of the GD field shown in this study was built based on data after processing, filtering and selection from an updated study on seismic, geological and core analysis elements, etc., as well as data from exploration and appraisal wells, GD-1X, GD-2X and GD-ST, and production wells, GD-1P and GD-2P.

The reservoir model was simulated in detail depending on the general flow in HU (hydraulic flow units) with different porosity-permeability characteristics. The HU facies were classified on the basis of applying a number of articles published in SPE [Abbaszadeh et al. (1996); Amaefule et al. (1993); Orodu et al. (2009); Shokir et al. (2006)], the core analysis results, well logging material and other supporting data. The model uses an SIS algorithm to simulate and research the interconnection between the oil body and the heterogeneity of the physical properties of rocks in Lower Miocene reservoir ILBH5.2.

\section{Analysis input data in parameter modeling}

\section{Physical lithologic parameter from well log curves}

IP software was used to interpret well log data for all wells in the GD field. GR, density and neutrons are the main tools to determine the top and base of the reservoir. The interpretation is fit with the core sample, results of the core analysis, results of interpretation and the resulting pressure reservoir testing.

The ILBH5.2 reservoir in all five wells, GD-1X, GD-2X, GDST, GD-1P and GD-2P, in particular and the GD field in general have low resistivity ranges from 2-6 O and product seams with a thickness ranging from very thin $(0.5 \mathrm{~m})$ to more than tens of meters. Similarly, because of the thin reservoir, low resistivity, single sand body and multilayer reservoir system in the neighboring fields in Cuu Long Basin, the identification and analysis of reservoir oil bearing sands in the GD field also suffer certain difficulties. Therefore, before interpretation it is necessary to consider the correlation factors caused by low resistivity such as the effect of noise on the well log curve, permeable zone, thin reservoir, secondary minerals (pyrite) and other correlations.

\section{Well log interpretation results}

Well logging interpretation results in the entire section of wells showed that the main product reserves of the GD field are terrigenous sandstone of the bottom of the Lower White Tiger Formation (ILBH5.2) of Early Miocene age. There is also terrigenous sandstone belonging to the Middle of the Lower White Tiger Formation (ILBH5.1) and Early Miocene C Class of the Upper Tra Tan Formation of the Late Olioxen contained in the product. Generally sandstone of the GD field is cleaner and of better quality than the field in the neighborhood.

Only a few oil reservoirs were encountered in the wells of ILBH5.1. The sandstone reservoirs are generally thin and poor quality with an average porosity of $16-18 \%$ and high water saturation (above 50\%), and oil mobility from the pressure test along the borehole (RCI) is small $(<10 \mathrm{mD} / \mathrm{Cp})$. No core samples were taken for this object in the field.

The quality of the reservoir of the Lower White Tiger Formation (ILBH5.2) is from good to very good, especially the upper part of ILBH5.2 in all wells. The oil body in the upper part of ILBH5.2 has thickness ranging from 1.5-8 m, average porosity of $20-23 \%$, average water saturation of $32-38 \%$ and permeability from the core analysis results of about 100 to several hundred $\mathrm{mD}$, up to a couple of Darcy. Results of reservoir testing with 8000 barrels/day in GD- 
$1 \mathrm{X}$ confirmed the possibility of a very good flow of this formation. The oil body in the lower part of ILBH5.2 has a thickness from 0.5 to $5 \mathrm{~m}$, average porosity of $18-21 \%$, average water saturation of $37-45 \%$ and permeability from the core analysis results a few dozen to a few hundred $\mathrm{mD}$.

The oil reservoir encountered in the Oliocene $\mathrm{C}$ reservoir has average to good quality, average porosity of $17-19 \%$ and average water saturation of $45-55 \%$, and results for permeability from the core analysis of GD-4X at the South Field are a few dozen mD.

\section{Lithology parameter from core analysis}

Typically, the oil and gas discoveries, before going on to the development stage, require core sampling to conduct research to clarify the mechanical properties of the reservoir. The results of this study are not only related to a correct effect of well log interpretation but also to providing input data for the field model and orientation for future development.

In the northern GD field region, 27-m core samples were taken in the ILBH5.2 reservoir at GD-2X wells. The core samples were also taken from most sections of the ILBH5.2 and C-Oliocene oil reservoirs in wells in the GD field region.

Concerning the results of facies interpretation, the sedimentary environment on the core samples showed that the ILBH5.2 reservoir was deposited in rivers and lakes, which characterized the facies forms as related to the ancient riverbed. The results of this interpretation guided the construction of the facies distribution model in the next step.

Results of routine core analysis in the laboratory showed that the permeability of ILBH5.2 ranged from good to very good. Porosity values measured in the sand body ranged from 12 to $26 \%$, permeability ranged from a few dozen to several hundred $\mathrm{mD}$, and some places showed up to several Darcy. Considering this porosity-permeability relationship, combined with well logging data and other supporting data to allow dividing rocks into facies, a hydraulic unit with different permeability characteristics will be discussed in detail in the next section (Fig. 3).

Special core analysis (SCAL) is also carried out to provide input to the simulation models to exploit the latter as determining capillary pressure $(P \mathrm{c})$ and relative permeability, etc. Curves of capillary pressure with water saturation (Fig. 4) were then built corresponding to the high level of oil gradation maximum water in five permeability ranges as follows:

- Permeability $>1000 \mathrm{mD}$

- Permeability $\leq 1000 \mathrm{mD}$ to $>200 \mathrm{mD}$

- Permeability $\leq 200 \mathrm{mD}$ to $>50 \mathrm{mD}$

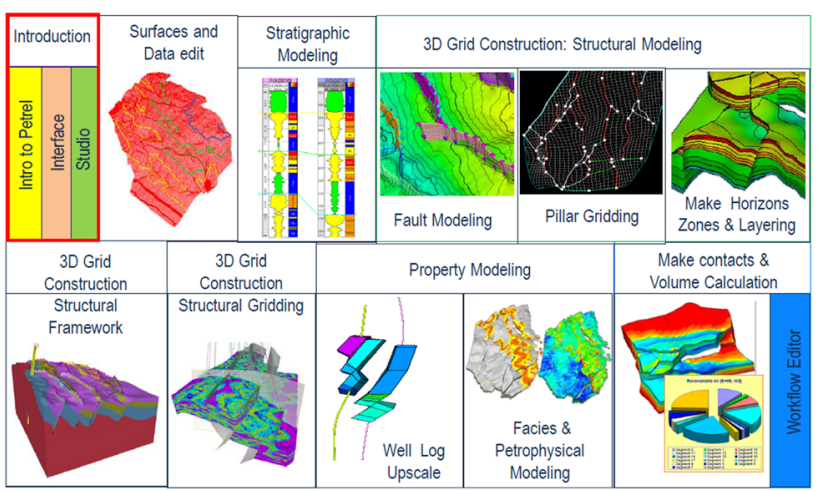

Fig. 3 Steps of the 3D modeling of the GD reservoir (Schlumberger 2010)

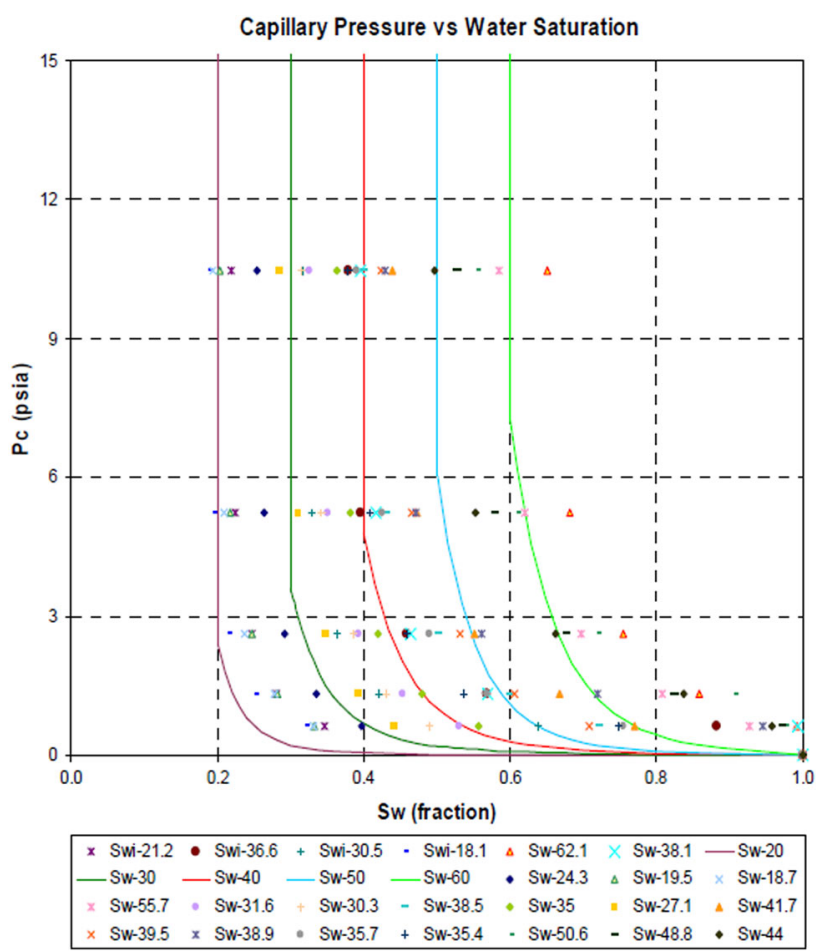

Fig. 4 Curves of capillary pressure with water saturation

- Permeability $\leq 50 \mathrm{mD}$ to $>10 \mathrm{mD}$

- Permeability $\leq 10 \mathrm{mD}$

\section{Application in parameter modeling}

The physical results of lithological analysis, core samples and other supporting studies will be synthesized for use as input data for the simulation of the physical lithology characteristics of the lower Miocene reservoir ILBH5.2. The basic parameters to be modeled are: distribution of facies, porosity, permeability and water saturation. Applying these analyses results in each specific parameter model as follows: 


\section{Facies modeling}

In the field development phase, the parameter model must be elaborated to obtain the best results for the physical lithology characteristics of the reservoir. Thus, the facies modeling not only simulates two types of rocks, but is also necessary to modeling in a new direction to be able to more clearly reflect the level of interconnection of the oil body as well as the heterogeneity of the reservoir characteristics.

Results of interpretation of environmental facies from core sample data show that more than ten kinds of environmental facies rivers/lakes were identified in the study area. However, predicting this kind of facies in the space of coring in wells and then simulated reservoirs as depositional facies faces many difficulties. Therefore, the simulation under lithology facies included reservoir and non-reservoir rocks but split reservoir rocks into different HU types based on their porosity-permeability characteristics derived from core analysis results used in facies modeling steps.

The modeling distribution by HU type in geologic modeling is only applied by a few operators for oil and gas fields in Vietnam. The advantage of this approach is reflected quite clearly: the degree of heterogeneity of reservoir rock distribution and the lithological physical parameters, especially permeability. Although there were significant advantages and other methods, prediction of the facies distribution in drilling locations still has certain limitations and should be verified by the new wells.

While convention applies to the majority of the world's oil, the critical value for the permeability of reservoir rock is $1 \mathrm{mD}$ for terrigenous sediments. Stones with less than $1 \mathrm{mD}$ permeability will be said to be non-reservoir. From the results obtained from core analysis of wells in the study area, the effective porosity values $(\Phi)$ ) and permeability $(K)$, after eliminating the permeability values less than $1 \mathrm{mD}$, will be used to calculate the RQI (reservoir quality index) and FZI (flow zone indicator), respectively, based on the following equation [Abbaszadeh et al. (1996); Amaefule et al. (1993); Orodu et al. (2009); Shokir et al. (2006)]:

$\mathrm{RQI}=0.0314 \sqrt{\frac{K}{\Phi e}}$

$\mathrm{FZI}=\frac{\mathrm{RQI}}{\Phi z}$

where:

$\Phi z=\frac{\Phi e}{1-\Phi e}$

The calculated FZI value will be shown on the chart according to the statistical probability as shown in Fig. 5 to determine the amount of HU from core analysis data. Figure 5 shows that rocks can be grouped into four types of $\mathrm{HU}$ corresponding to four lines with different slope angles

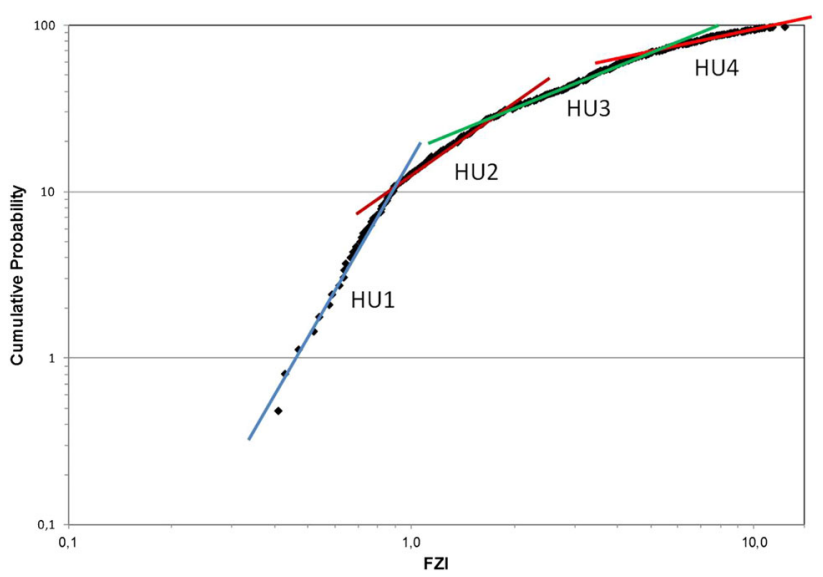

Fig. 5 Determined number of HU types from core data

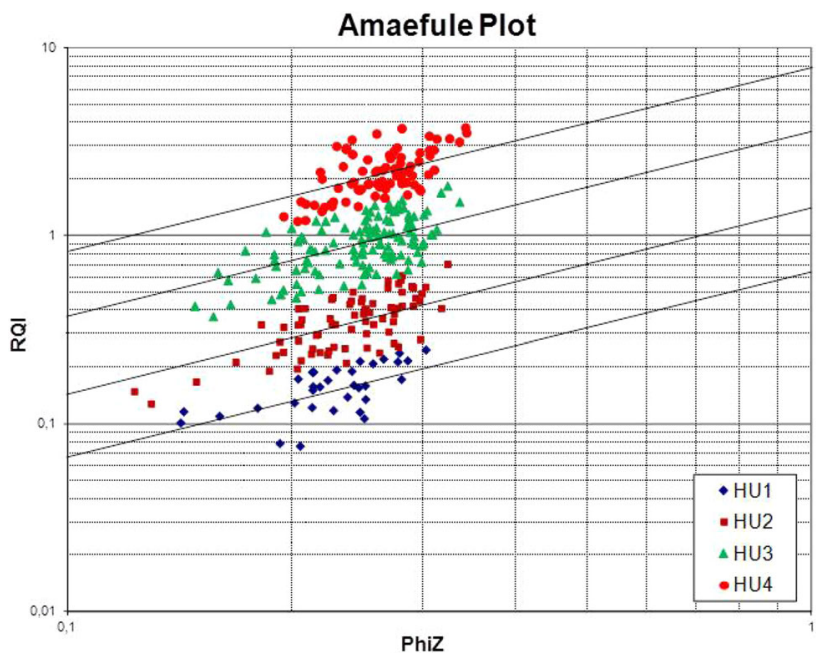

Fig. 6 HU types from core data

representing each $\mathrm{HU}$. The newly identified type of HU can then be shown in the Amaefule plot according to the relationships between the reservoir rock quality index (RQI) and porosity regulations (normalized porosity, $\Phi \mathrm{z}$ ) for the entire core as illustrated in Fig. 6.

The division of facies into HU types also refers to the results of interpretation of sedimental environment facies from core sample data in the wells. Figure 7 shows the results for the facies divided into HU types are quite consistent with the results of the analysis of sedimentary facies. HU types 3 and 4 correspond to the channel fill, gravity flow and mouth bar facies-rocks of sedimentary facies types that have good to very good permeability quality. The reservoir rock facies category with average permeability such as crevasse splay and hyperpycnal flow was mainly located in HU type 2. The rocks of sedimentary facies have low permeability such as sheet flood and the bank over related to $\mathrm{HU}$ type 1 or non-reservoir rock (Fig. 8). 


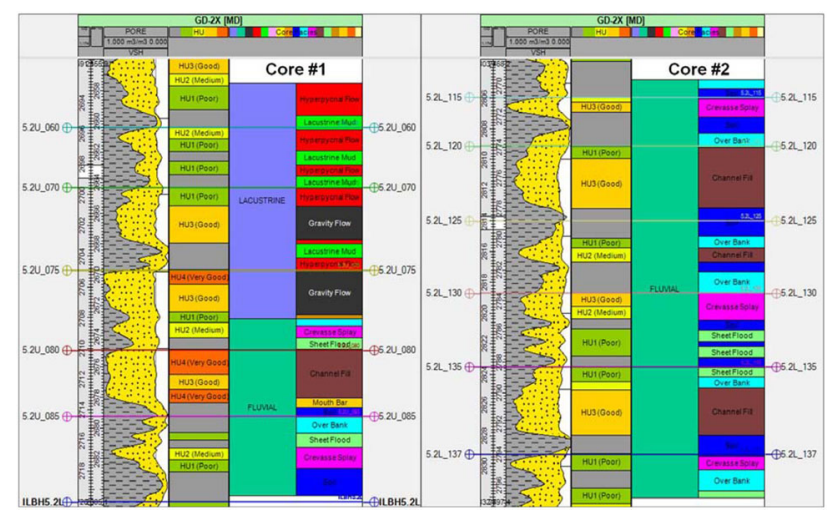

Fig. 7 Comparison of HU types with sedimental facies from core interpretation

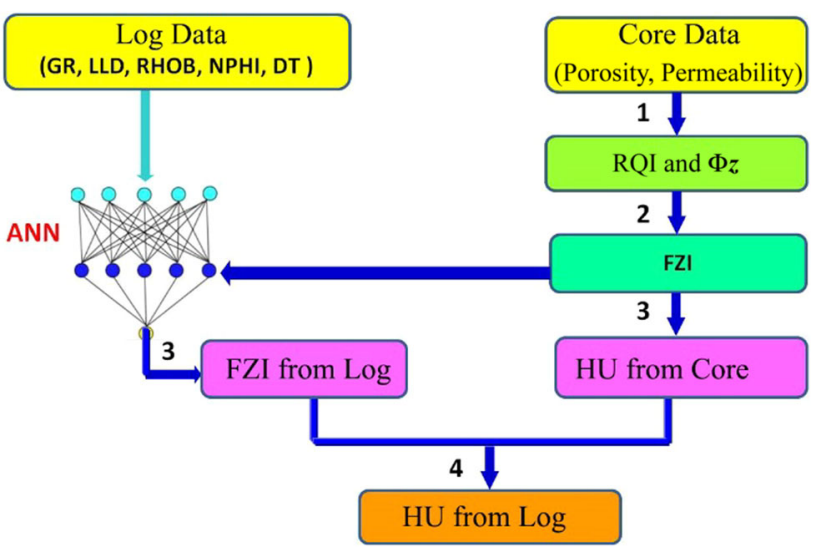

Fig. 8 Predicted FZI values by the artificial neutron network method (ANN) in IP

The division results of reservoir rock into four HU types from the core data mentioned above were combined with the curves of well logging such as GR, deep resistance, density, neutrons and ultrasound using the artificial neuron network method (ANN) in IP software to predict the FZI values and then grouped by HU type for space with no core sample in well sections following these steps:

Typically in facies modeling, the results of seismic data interpretation in particular are used to orientate the distribution of facies over the area if these data demonstrate the morphology of the sedimentary environment consistent with the results of the wells. However, in the GD field, many studies of seismic attributes have been deployed but the results show or do not show the form of the sedimentary environment or are inconsistent with the results of wells. So, in the process of facies modeling for Lower Miocene reservoir ILBH5.2 in the north of the GD field, the results of the research, in particular the seismic attributes, were not used when simulating facies.

To overcome this problem, the trend of the distribution map of each HU type for each reservoir has been built on

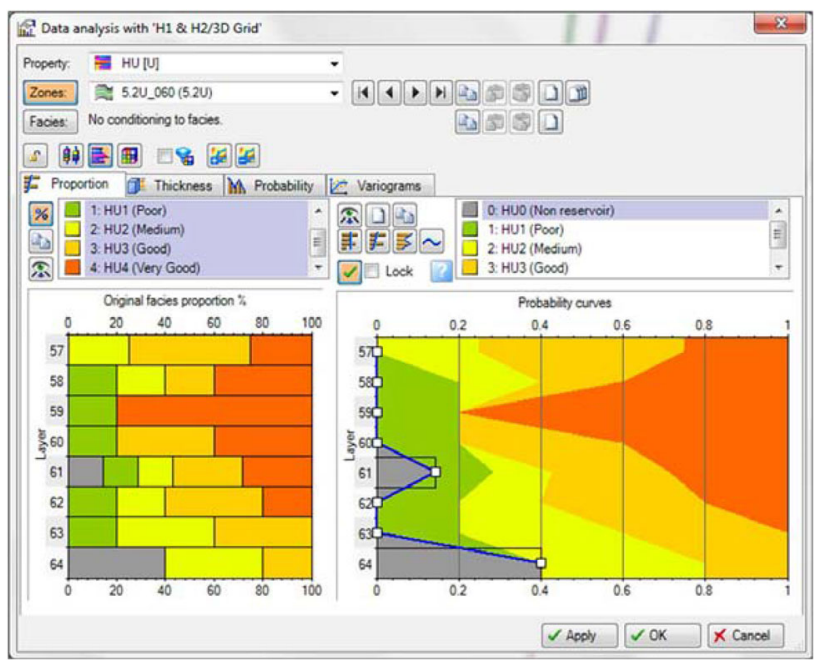

Fig. 9 Distribution of each HU type with each zone in ILBH5.2U_060

the well logging interpretation results to orientate their distribution in the process of simulating facies. The orientation maps show the probability distribution of each HU type in each reservoir all over the GD field. They are built for the GD field based on the rate of each HU type in each reservoir in all wells. These maps will partially control the distribution of the HU type according to area. The probability distribution of each $\mathrm{HU}$ type in vertical orientation in each reservoir is also based on the rate of each HU type distribution per layer in the well (Fig. 9).

Figure 10 shows the distribution trend map of an $\mathrm{HU}$ type in the GD field. Figure 10 shows that the probability distribution of HU type 3 of the ILBH5.2U_030 reservoir in the eastern region will be larger than in the western region.

To control the interconnection as well as the heterogeneity of rocks upon area as well as vertical direction, the correlation of data pairs was included in the survey (variograms) in the main direction, toward the sub-direction and vertical direction.

The actual documents from the wells in the GD field showed that horizontal values of variogram modeling cannot be built because of the limitations of the number of wells as well as the linear distribution of the wells. Hence, the value of horizontal variograms used in statistical models from the field in the area adjacent to the main direction variogram value was from 1400 to $1800 \mathrm{~m}$ and of accessories from 800 to $1200 \mathrm{~m}$ direction depending on the thickness of the sand bodies in each reservoir. Environmental studies of the sediment in the block 16.1 area as well as flow interpretation from the FMI data of wells in the GD field show the sediment transport direction is from north-northwest to south-southeast, so the main direction of 


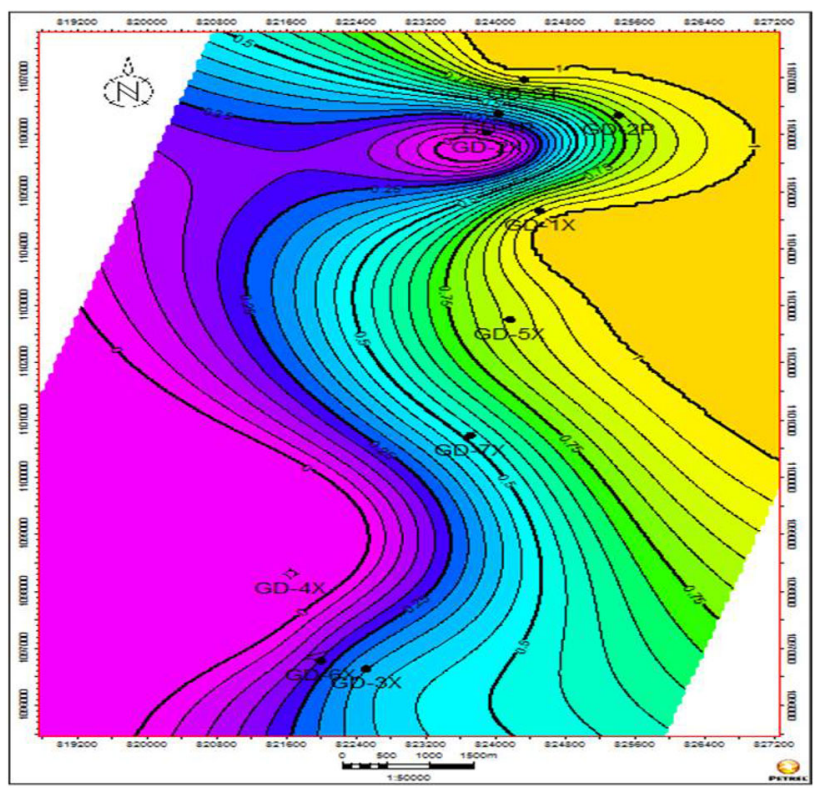

Fig. 10 Map distribution tendency of three types of $\mathrm{HU}$ in area ILBH5.2U_030

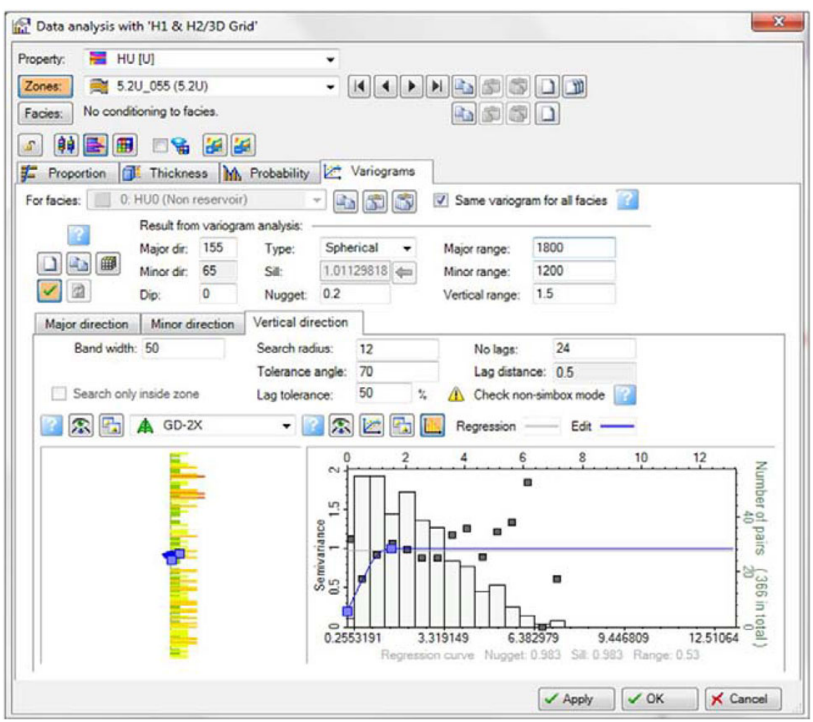

Fig. 11 Variogram survey in the vertical direction in the ILBH5.2U_055 reservoir

horizontal variograms is NNW-SSE as the material transport direction.

The values of vertical variograms were surveyed on the basis of the actual well data. The vertical variograms can be models for most of the reservoirs in the model, despite the anisotropy and cyclical nature of the data. Each reservoir is examined in vertical variograms for all HU types from well data of that reservoir as illustrated in Fig. 11. Results of the variograms for the vertical direction in the wells ranged from 1 to $2 \mathrm{~m}$. The results of stimulation for

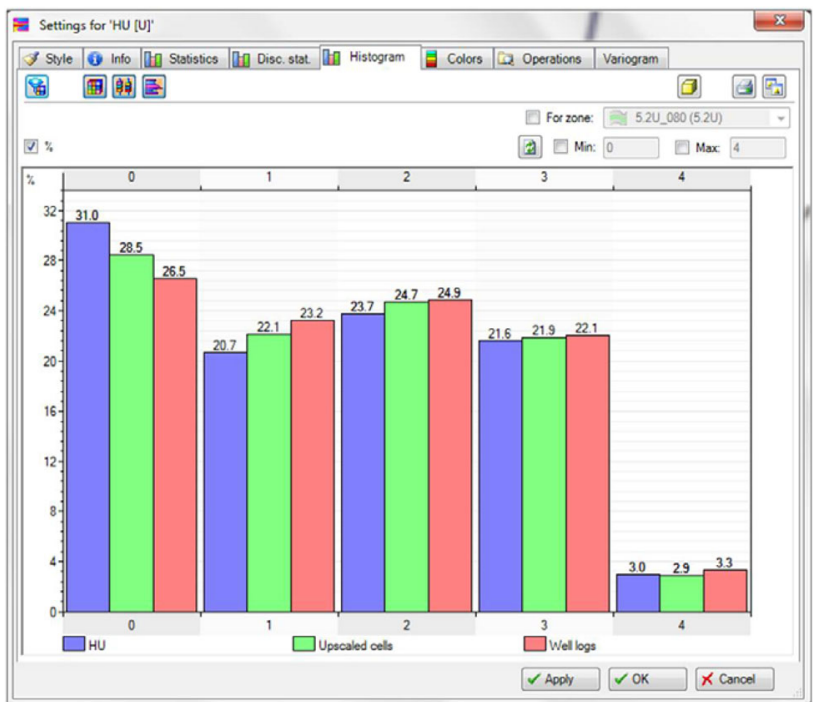

Fig. 12 Comparison of charts of $\mathrm{HU}$ types before and after stimulation

the facies distribution model for each HU type in ILBH5.2 in the north of the GD field are shown in Figs. 12 to 13 below.

\section{Porosity model}

The porosity distribution model is built on the basis of porosity curves after averaging using the random simulation method according to SGS algorithms and references the facies distribution model. If the stone does not contain (HU0), the porosity will be assigned a value of 0 (Figs. 14, 15).

Before conducting the simulation, the data are converted to standard distribution (normal score) for each type of $\mathrm{HU}$ in each reservoir. Figure 16 is an example of the transformation of data in ILBH5.2U_085 reservoir for HU type 3 before the porosity simulation.

Similar to facies distribution modeling, due to the limited number of wells, the values of horizontal variograms used in porosity modeling from the adjacent field are also shown statistically. Values of variograms in the main direction for the reservoir varies from 1200 to $1600 \mathrm{~m}$ and accessories from 600 to $1000 \mathrm{~m}$ direction depending on the thickness of the sand bodys at each reservoir. The values of vertical variograms were surveyed for each HU type in each reservoir zone on the basis of the actual well data (Fig. 17). Values of vertical variograms for reservoirs according to a survey in the wells ranged from 0.8 to nearly $2 \mathrm{~m}$.

The results of porosity distribution modeling for ILBH5.2 in the north of the GD field are shown in Figs. 18, 19, 20 and 21 below. 


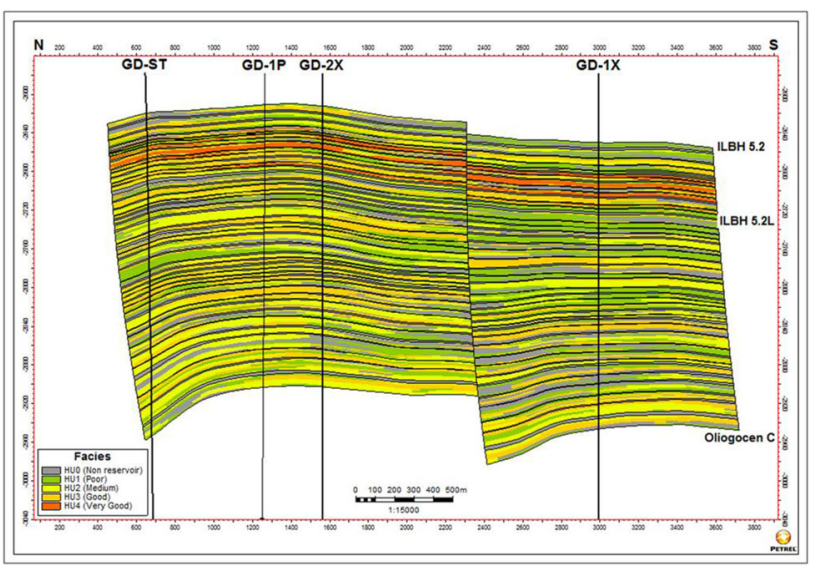

Fig. 13 North-south section's facies distribution

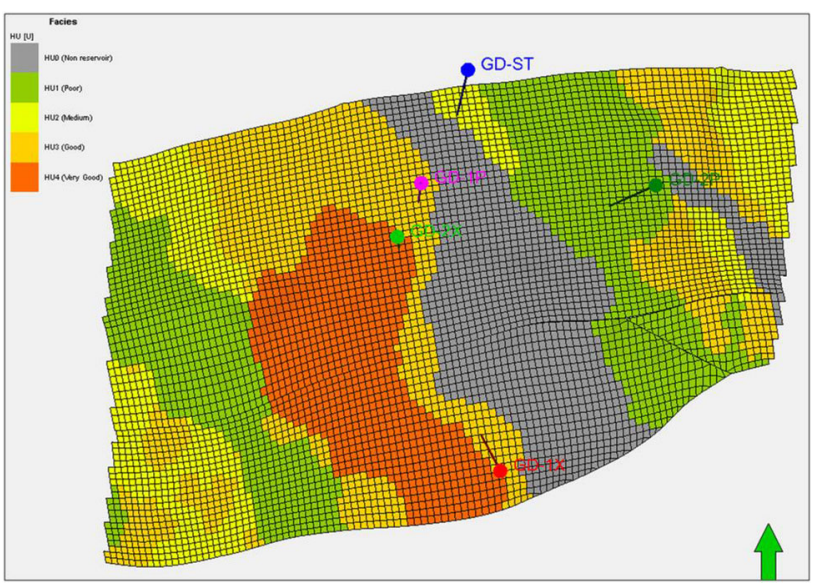

Fig. 14 Facies distribution according to the area in ILBH5.2U_075 reservoir

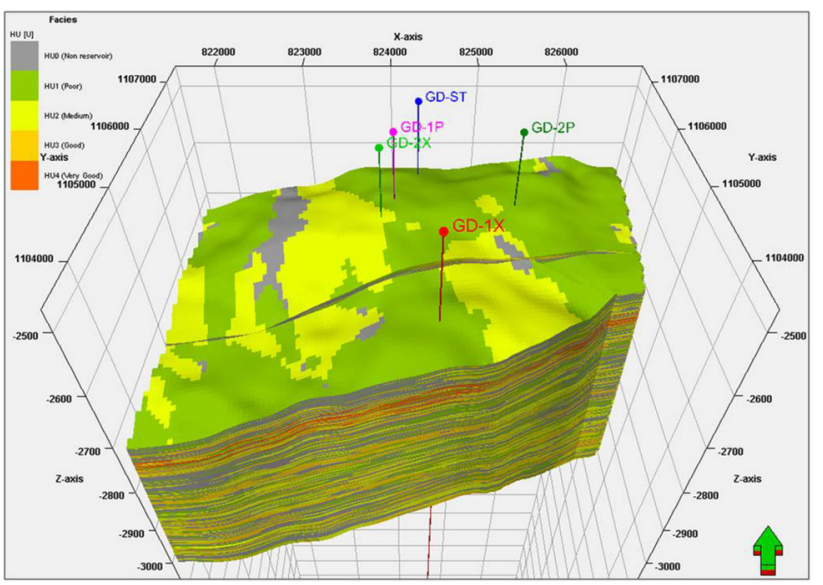

Fig. 15 The 3D model shows the distribution of rock facies

\section{Permeability model}

On the basis of the identified HU type, a porosity-permeable relationship by HU type was built and is shown in

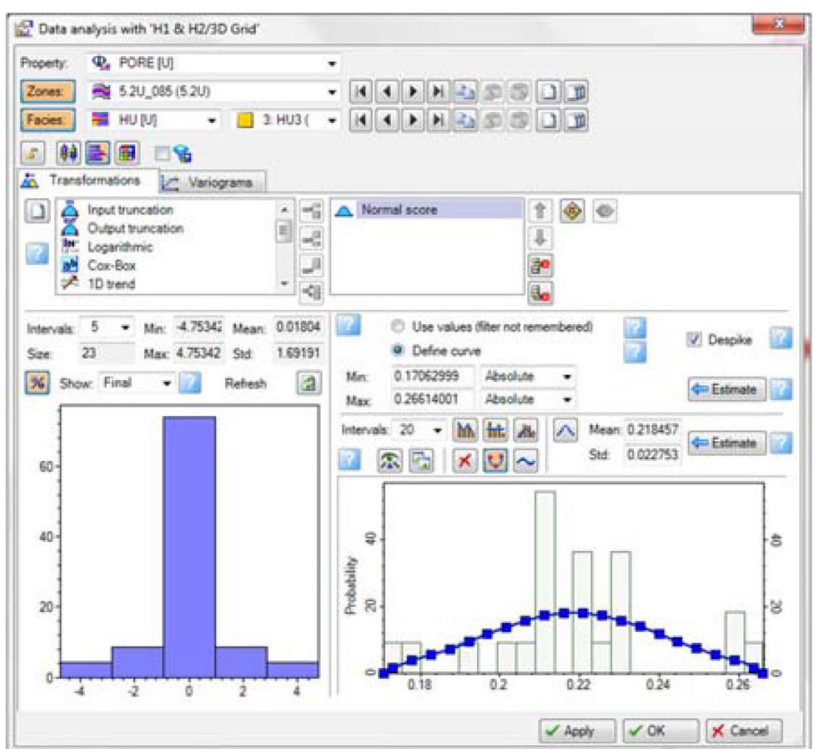

Fig. 16 Covert porosity data of the standard distribution function (normal score) for HU type 3, ILBH5.2U_085 reservoir

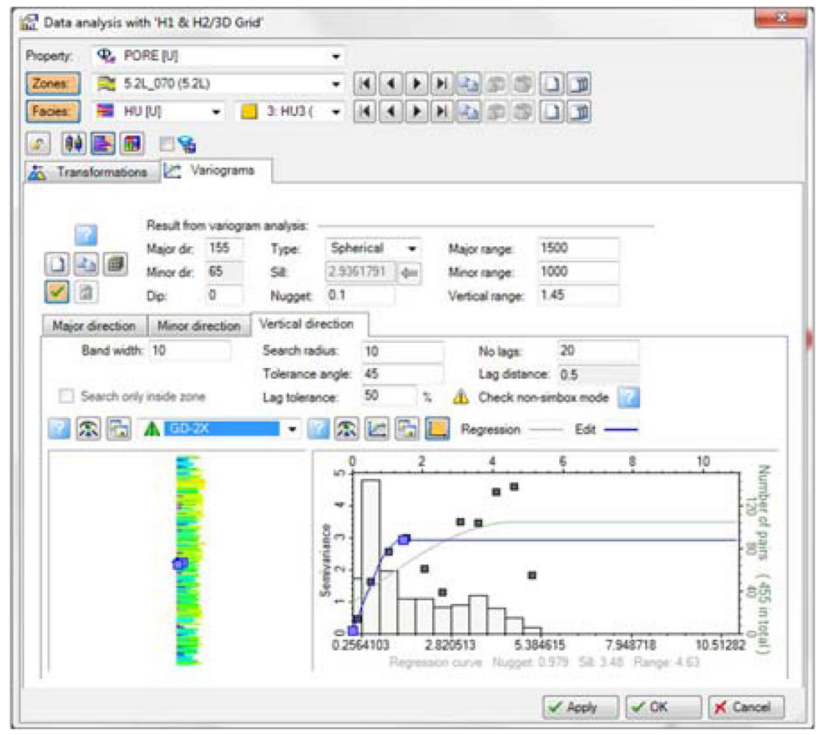

Fig. 17 Vertical variogram survey for HU type 3, ILBH5.2L_070

Fig. 22. Figure 22 shows that if we group rocks into a single type, then according to this relation, the permeability variability at a porosity value would be enormous.

After the porosity model was simulated, the permeability model was modeled directly from the porosity model using porosity-permeability relationships established for each type of HU (Fig. 22) on the basis of the empirical equations of Carman-Kozeny:

$K=1014 * \mathrm{FZI}^{2} * \frac{\Phi_{e}^{3}}{\left(1-\Phi_{e}\right)^{2}}$

Thus: 


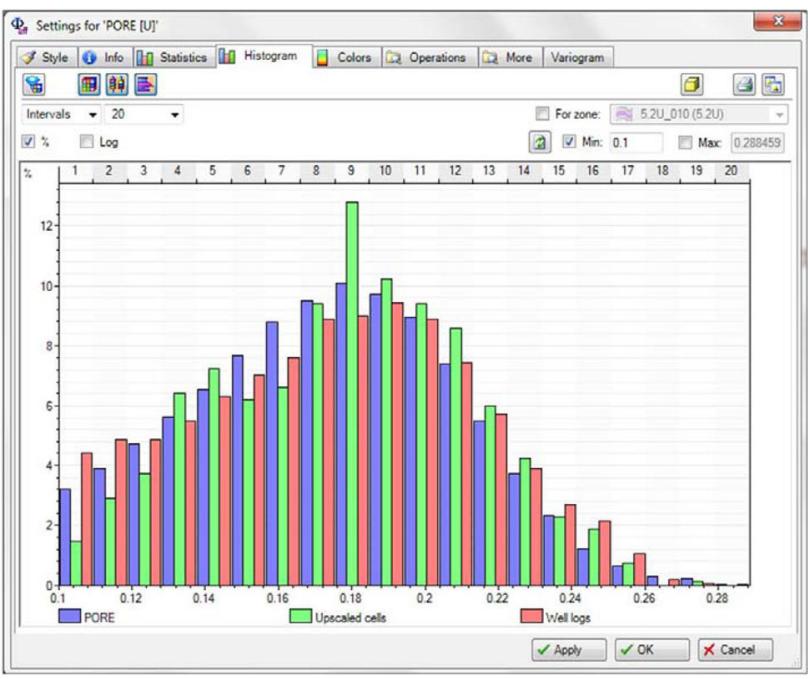

Fig. 18 Comparison of chart porosity characteristics before and after stimulation

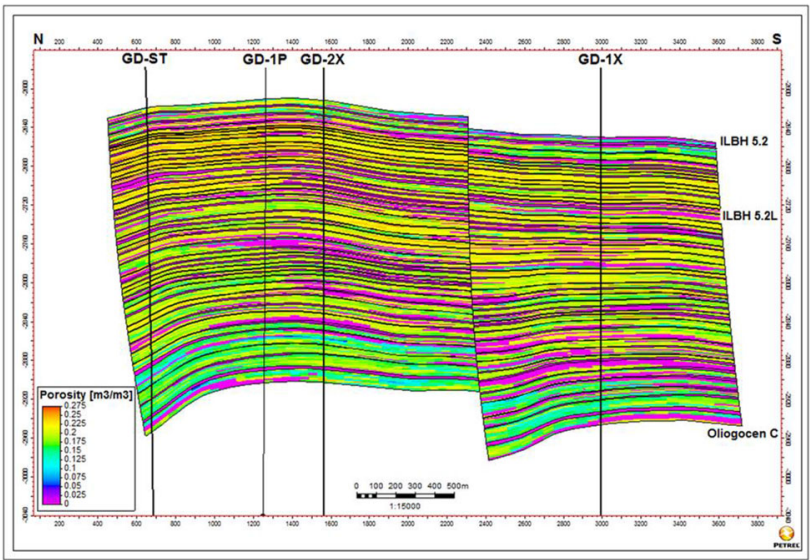

Fig. 19 North-south section shows the porosity distribution

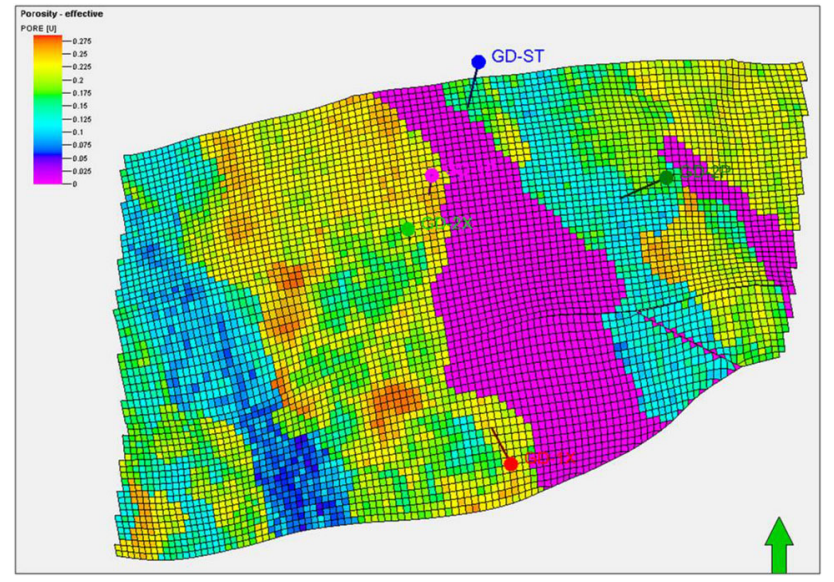

Fig. 20 The distribution of porosity according to area in the ILBH5.2U_075 reservoir

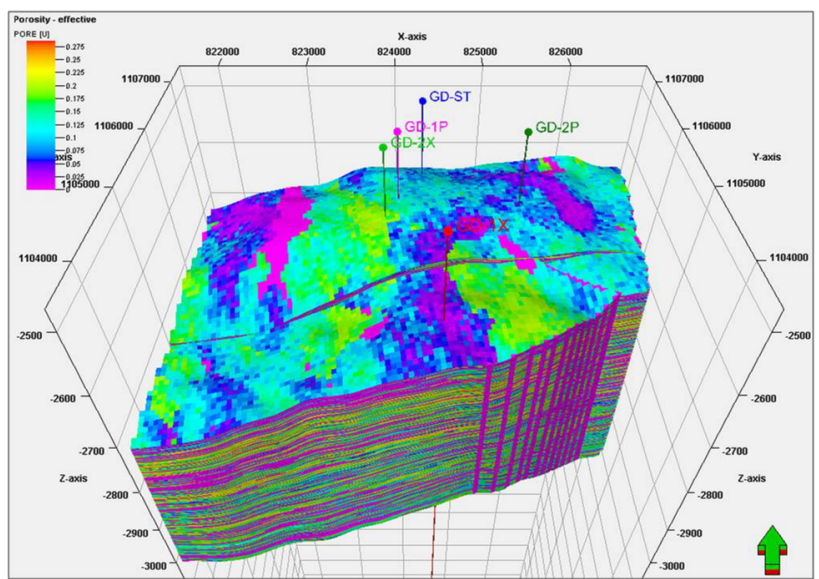

Fig. 21 THe 3D model shows the porosity distribution

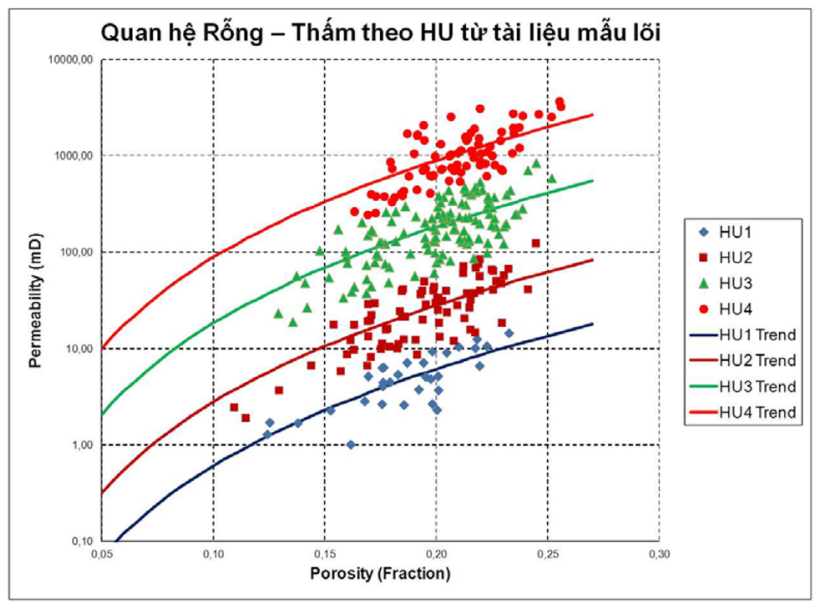

Fig. 22 Porosity-permeability for each HU type from the core data

For HU type 1: Permeability $=1014 * 0,694263 *$ Pore^3/(1-Pore $)^{\wedge} 2$

For HU type 2: Permeability $=1014 * 1,486283^{*}$ Pore^3/(1-Pore $)^{\wedge} 2$

For HU type 3: Permeability $=1014 * 3,810493 *$ Pore^3/(1-Pore $)^{\wedge} 2$

For HU type 4: Permeability $=1014 * 8,388943 *$ Pore $^{\wedge} 3 /(1-\text { Pore })^{\wedge} 2$

Results of the permeability distribution modeling for the ILBH5.2 reservoir in the north of the GD field is shown in Figs. 23, 24 and 25 below.

\section{Water saturation}

Unlike permeability or porosity, the water saturation model change depends on the height of the oil body. The water saturation modeling based on the saturation curve results from well $\log$ interpretation using the random simulation 


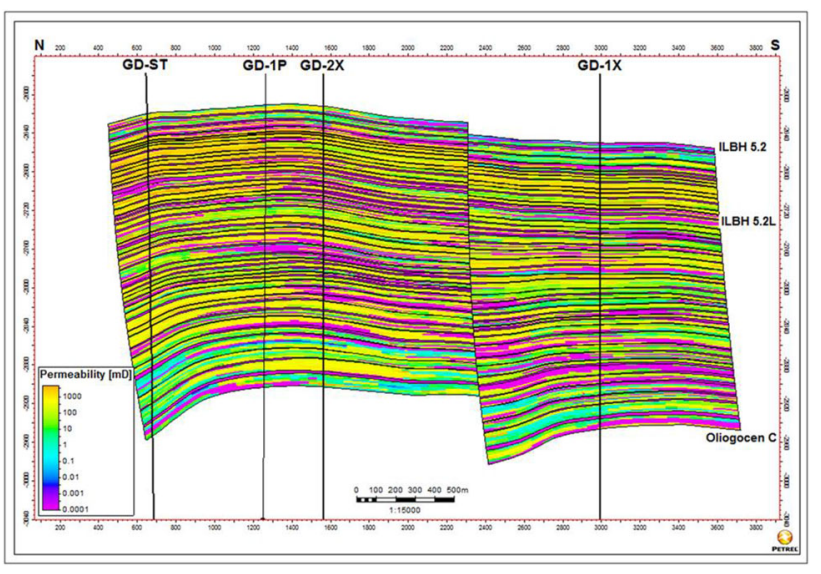

Fig. 23 North-south section shows the permeability distribution

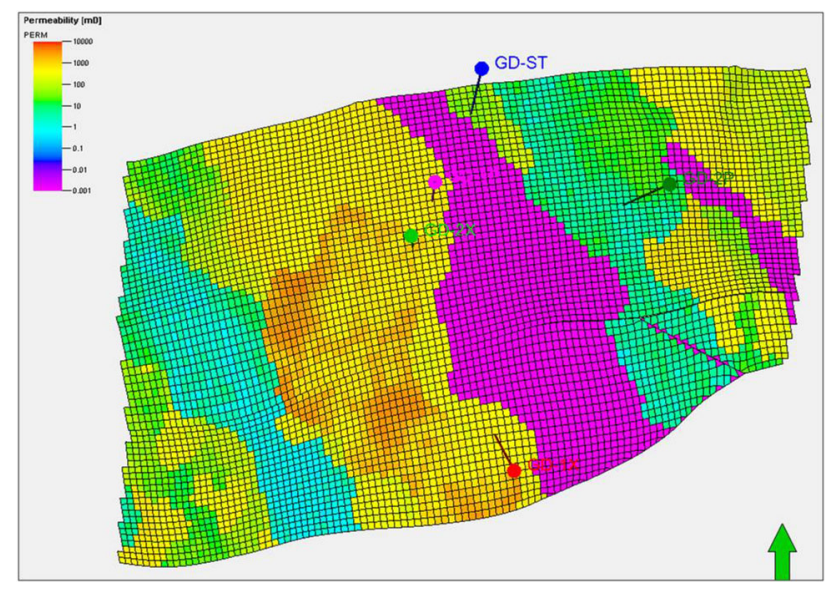

Fig. 24 Permeability distribution according to area for ILBH5.2U_075

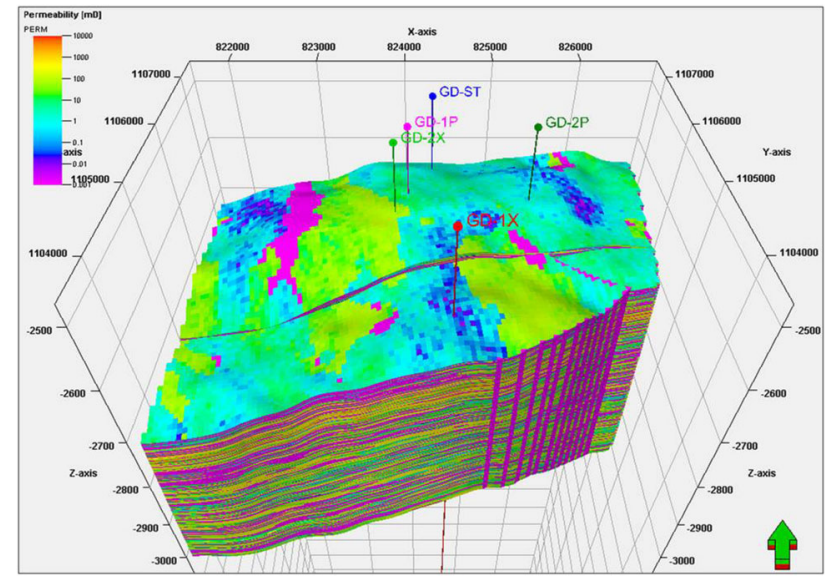

Fig. 25 The 3D model shows the permeability distribution

method, which is difficult to express. Therefore, the result of water saturation $\mathrm{Sw}$ from well log interpretation applies only to the reserve calculation using the volume method

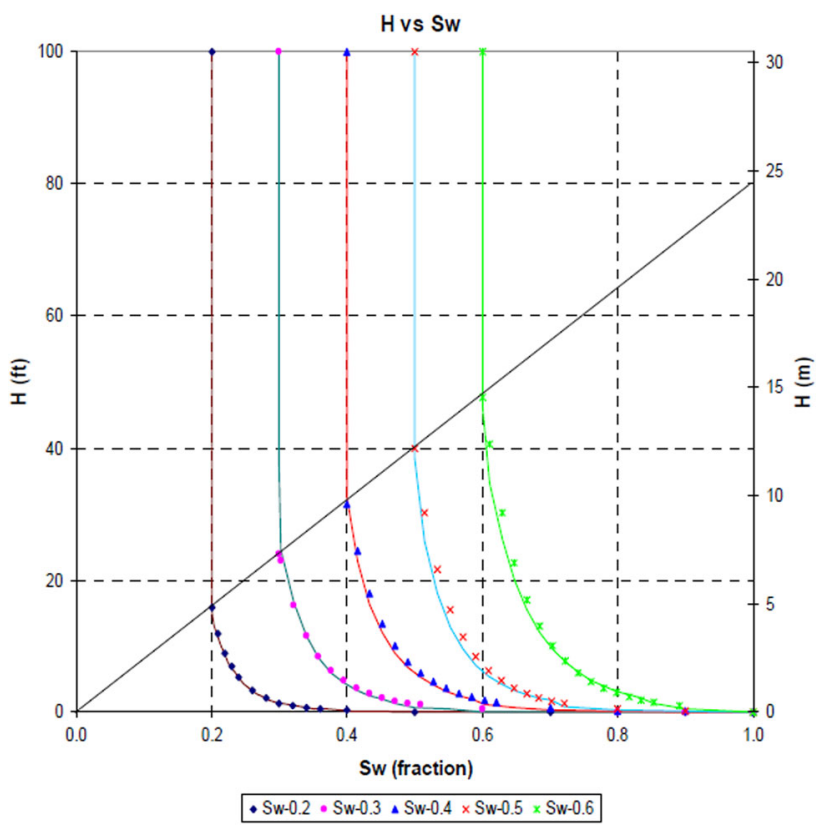

Fig. $26 \mathrm{Sw}$ curves as the height of the oil body

and compared with the results of the water saturation model in the well locations.

From the capillary pressure curve obtained from SCAL, the saturation level according to the oil body height (SwHeight), as shown in Fig. 26, is built for five different permeability ranges, corresponding to the capillary pressure curve as mentioned above. On the basis of the content of this function, combinations with permeability models were simulated, and then the water saturation model was simulated.

A model of water saturation $(\mathrm{Sw})$ is simulated using direct water saturation functions with the oil body height (Sw-Height) and the permeability distribution model is then built. The saturation function with height $(h)$ of the oil body in the upper part of the free water level (Height above FWL) was built for five different permeability ranges corresponding to five capillary pressure curves according to the next function:

Permeability $\geq 1000 \mathrm{mD}$ :

$\mathrm{Sw}=0.317 / \mathrm{h}^{\wedge} 0.1667$ and minimum $\mathrm{Sw}=20 \%$ if $h \geq 4.8 \mathrm{~m}$

Permeability from 200 to $<1000 \mathrm{mD}$ :

$\mathrm{Sw}=0.516 / \mathrm{h}^{\wedge} 0.171$ and minimum $\mathrm{Sw}=30 \%$ if $h \geq 7.3 \mathrm{~m}$

Permeability from 50 to $<200 \mathrm{mD}$ :

$\mathrm{Sw}=0.655 / \mathrm{h}^{\wedge} 0.143$ and minimum $\mathrm{Sw}=40 \%$ if $h \geq 9.6 \mathrm{~m}$

Permeability from 10 to $<50 \mathrm{mD}$ :

$\mathrm{Sw}=0.74 / \mathrm{h}^{\wedge} 0.106$ and minimum $\mathrm{Sw}=50 \%$ if $h \geq 12 \mathrm{~m}$ 


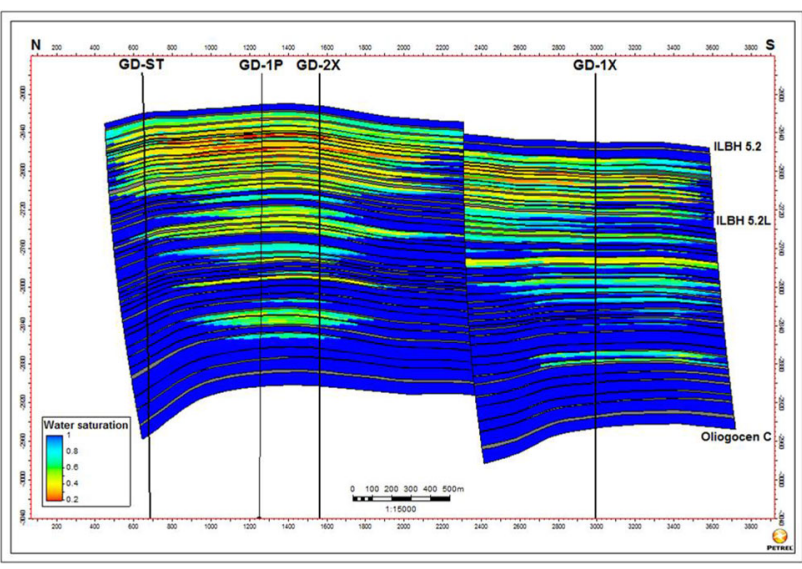

Fig. 27 The north-south section shows the water saturation distribution

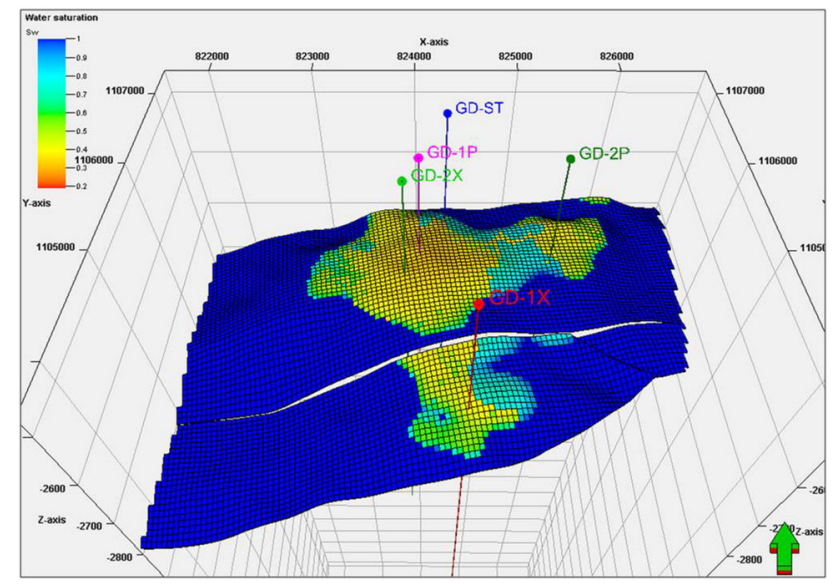

Fig. 28 Water distribution according to area at ILBH5.2U_075

Permeability $<10 \mathrm{mD}$ :

$\mathrm{Sw}=0.89 / \mathrm{h}{ }^{\wedge} 0.102$ and minimum $\mathrm{Sw}=60 \%$ if $h \geq 14.5 \mathrm{~m}$

Based on this saturation function, combination with the permeability models was simulated and then the water saturation model was simulated. Results of the water saturation distribution model for ILBH5.2 in the north of the GD field are shown in Figs. 27, 28 and 29 below.

\section{Calculate oil initially in place from the 3D model}

Oil initially in place is calculate by the following formula:

$\mathrm{OIIP}=\mathrm{BRV} * \mathrm{NTG} *$ Pore $*(1-\mathrm{Sw}) / \mathrm{Bo} * \mathrm{C}$

Where:

- OIIP: Oil initially in place (milion barrels)

- BRV: Volume of reservoir rock (million $\mathrm{m}^{3}$ )

- Pore: Effective porosity.

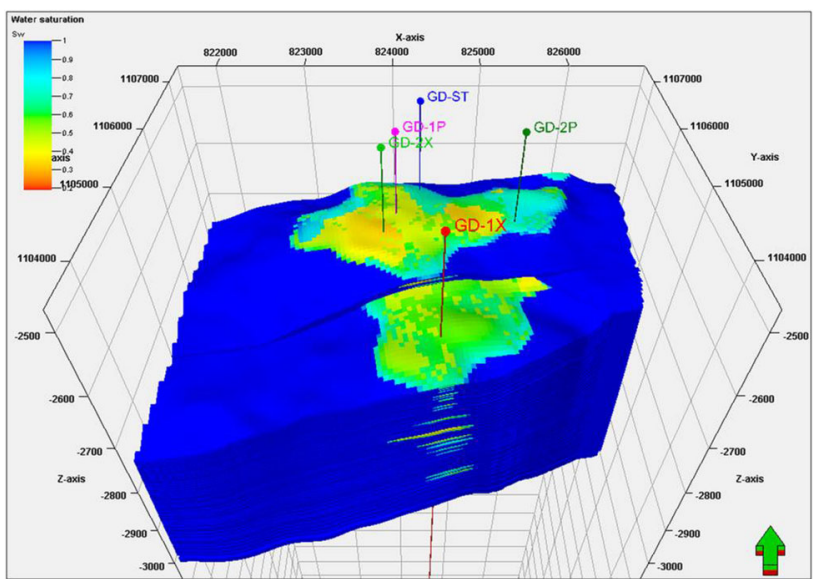

Fig. 29 The 3D model shows the water saturation distribution

- NTG: Ratio between effective thickness and total thickness.

- Sw: Water saturation.

- Bo: Volume factor (rb/stb).

- C: Covert coefficient from $\mathrm{m} 3$ to bbl.

Before calculating the oil reserves in place, NTG models are built on the basis of the facies distribution model, and then there will be purging if the valuable grid does not correspond to the critical value (cutoff) of porosity (less than $10 \%$ ) and saturation (greater than $70 \%$ ) is similar to the volume calculated by the volumetric methods. Also the grid with smaller permeability values of $1 \mathrm{mD}$ will be removed, although the number of grid cells in the model is negligible.

Based on the facies model and the porosity, a saturation parameter model has been built, and in-place oil reserves will be calculated using the volumetric calculation function in Petrel software. One hundred scripts (realization) were run, and the base case corresponding to the P50 probabilistic results to use in simulation production models was chosen.

Results for the oil reserves in place for the P50 probability for ILBH5.2 in the north of the GD field are shown in Table 1. The distribution of oil reserves in 3D space is shown in Fig. 30 below.

Table 1 Oil initially in place reserve

Oil initially in place reserve (MMSTB)

\begin{tabular}{lllc}
\hline Reservoir & $\mathrm{H} 1$ & $\mathrm{H} 2$ & $\mathrm{H} 1+\mathrm{H} 2$ \\
\hline ILBH5.2 upper & 51.4 & 16.1 & 67.5 \\
ILBH5.2 lower & 20.3 & 17.2 & 37.5 \\
Total & 71.7 & 33.3 & 105.0 \\
\hline
\end{tabular}




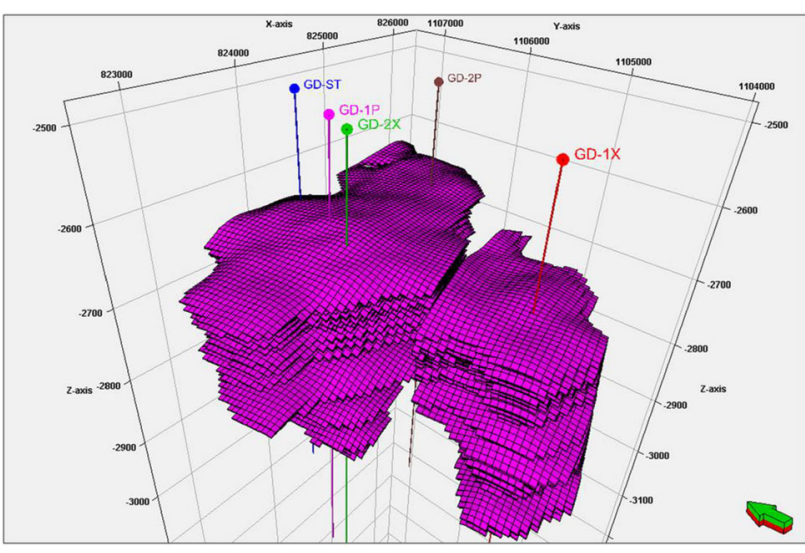

Fig. 30 The 3D model of oil initially in place reserve ILBH5.2

Compared to the calculated result using the volume method for block $\mathrm{H} 1$ and $\mathrm{H} 2$ of 102 million barrels, the oil initially in place calculated from the model is larger than $3 \%$. There reliability is acceptable.

\section{Conclusions}

The GD field consists of a series of small oil accumulations located in Block 16-1, Cuu Long Basin. The storey main product in the sandstone quarry is of Early Miocene terrigenous age characterized by a multilayer reservoir system, different in terms of the hydraulic vertical and independently in each block.

Due to the complex nature of the typical sandstone reservoir, the distribution modeling only divides the material into two kinds of rocks and will not reflect the level of interconnection of the oil body or the heterogeneity of the reservoir characteristics. Therefore, the search for new solutions to solve this problem require urgency and practical management and efficient production, especially as the GD field is entering the early stages of exploitation. The successful application of modeling methods to facies distribution according to general flow (HU) in the GD field opened up a new direction for the construction of geological models for materials such as sandstones.

Based on the integrated study for the construction of a 3D geological model for the Miocene oil body in the reservoir in the North of GD field, some conclusions were reached:

1. The structural model includes 5 faults, 42 reservoirs and 290 classes that have been developed carefully and accurately with high reliability. The grid size of the models of $50 \times 50 \times \sim 0.7 \mathrm{~m}$ is appropriate for the size of the field and detailed enough to reflect the heterogeneity of the physical lithological parameters.

2. The model-simulated stone contains four different types of $\mathrm{HU}$ on the basis of their porosity-permeability characteristics, which clearly reflects the interconnection among the the oil bodies, heterogeneity of distribution and contribution of the rock's petrographic physical characteristics, which are especially important for the permeability parameters related to the ability to flow.

3. The physical model of the lithological parameters (porosity, permeability and water saturation) modeled by HU type has shown a truly sophisticated nature of the reservoir characteristics. The degree of permeability variation narrowed significantly when divided into four categories of $\mathrm{HU}$ rocks, which helps minimize errors in parameter modeling.

4. Oil reserves in place at the level of $2 \mathrm{P}$ from the model are 105 million barrels including 71.7 million barrels from block $\mathrm{H} 1$ and 33.3 million barrels from blocks $\mathrm{H} 2$. Compared with the results calculated by volumetric methods, oil initially in place reserves from the model are larger than about 3\%, which confirmed the reliability of the results.

Acknowledgements We gratefully acknowledge the research group of the Petroleum Geology Department-HCMUT the subsurface department of PVEP-POC for supporting the authors in carrying out the study. We also thank PVEP-POC for providing the data for our research.

Funding This research is funded by Vietnam National University HoChiMinh City (VNU-HCM) under Grant No. C2016-20-05.

Open Access This article is distributed under the terms of the Creative Commons Attribution 4.0 International License (http:// creativecommons.org/licenses/by/4.0/), which permits unrestricted use, distribution, and reproduction in any medium, provided you give appropriate credit to the original author(s) and the source, provide a link to the Creative Commons license, and indicate if changes were made.

\section{References}

Abbaszadeh Maghsood, Fujii Hikari, Fujimoto Fujio (1996) Permeability prediction by hydraulic flow units-theory and applications. SPE Form Eval 11(4):263-271

Amaefule JO, Altunbay M, Djebbar T, Kersey DG, Keelan, Keelan DK (1993) Enhanced reservoir description: using core and log data to identify hydraulic (Flow) units and predict permeability in uncored intervals/wells. Paper SPE 26436-MS, SPE annual technical conference and exhibition, Oct 1993

Orodu OD, Tang Z, Fei Q (2009) Hydraulic (Flow) Units determination and permeability prediction: a case study of Block Shen95, Liaohe Oilfield, North-East China. J Appl Sci 9:1801-1816

Schlumberger (2010) Petrel Structural and Property Modelling Manual. Schlumberger, Houston

Shokir EMEL-M, Alsughayer AA, Al-Ateeq A (2006) Permeability estimation from well $\log$ responses. J Can Pet Technol 45(11):41-46 